\title{
DETERMINATION OF TRACE ZINC IN WATER, SOIL AND RABBIT BLOOD SAMPLES USING CLOUD POINT EXTRACTION COUPLED WITH ULTRAVIOLET-VISIBLE SPECTROPHOTOMETRY
}

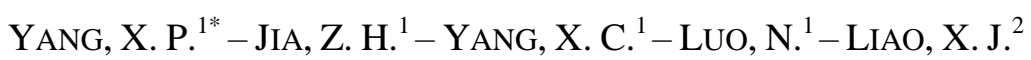 \\ ${ }^{1}$ College of Chemistry and Chemical Engineering, Chemical Synthesis and Pollution Control \\ Key Laboratory of Sichuan Province, China West Normal University, Nanchong 637000, China \\ ${ }^{2}$ Exposure and Biomonitoring Division, Health Canada, Canada \\ *Corresponding author \\ e-mail: xiupeiyang@163.com \\ (phone: +86-817-2568081; fax: +86-817-2568067) \\ (Received 22 ${ }^{\text {nd }}$ Jul 2016; accepted $9^{\text {th }}$ Nov 2016)
}

\begin{abstract}
An improved preconcentration method named as cloud point extraction (CPE) with ultravioletvisible spectrophotometry (UV-vis) has been developed for zinc preconcentration and determination. Non-ionic surfactant Triton X-100 was used as extractant based on the complexation reaction of Zn (II) ions with 1-(2-pyridylazo)-2-naphthol (PAN). Sodium dodecyl sulfate (SDS) and $\mathrm{NaCl}$ electrolyte solution worked as cloud point revulsant and synergic reagent, which successfully decreased the cloud point temperature (CPT) of Triton X-100 to $0{ }^{\circ} \mathrm{C}$. The enriched analyte in the surfactant-rich phase was determined by spectrophotometry at $549 \mathrm{~nm}$. The influence factors relevant to CPE were evaluated and optimized, including concentrations of Triton X-100 and SDS, concentration of chelating agent, $\mathrm{pH}$ as well as salt effect. Under the optimal conditions, the proposed CPE-UV-vis method showed linear calibration within the range $10-1000 \mathrm{ng} / \mathrm{mL}$ of $\mathrm{Zn}$ (II) and the limit of detection of the method was 3.3 $\mathrm{ng} / \mathrm{mL}$ with a preconcentration factor of 38 . The relative standard deviation (RSD) was found to be $2.8 \%$ $\left(\mathrm{C}_{\mathrm{Zn} \text { (II) }}=100 \mathrm{ng} / \mathrm{mL}, \mathrm{n}=11\right)$. The proposed method was applicable to the determination of trace levels of zinc in real water, soil and blood samples with satisfactory results.
\end{abstract}

Keywords: cloud point extraction; ultraviolet-visible spectrophotometry; 1-(2-pyridylazo)-2-naphthol; sodium dodecyl sulfate; environmental chemistry

\section{Introduction}

In recent years, the toxicity and the effect on human health and the environment of trace elements have been receiving growing attention in pollution and nutritional studies. Zinc is an essential trace element for humans, animals and plants that plays a key role in variety of physiological and pathological processes such as enzyme regulation, gene expression, catalytic function of the protein, apoptosis and so on (Falchuk, 1998; Berg and Shi, 1996; O’Halloran, 1993; Hambidge and Krebs, 2007; Vallee and Falchu, 1993). Disorders in zinc metabolism have led to several severe neurological diseases like Alzheimer, diabetes and epilepsy (Fischer-Walker and Black, 2004; Frederickson et al., 2005; Koh et al., 1996; Tsvetkov et al., 2008; Ho, 2004; Wei et al., 2004). Zinc deficiency can result in skin problems, slow healing of wounds, reduce the senses of taste and smell, increase susceptibility to infections, decrease fertility and loss of appetite and hair (Galbeiro et al., 2014). On the other hand, zinc is also a metal pollutant in the environment (Mansur et al., 2008; Wan et al., 2016). Too much zinc may impact the soil microbial activity and cause phytotoxic effects. Therefore, there is an increasing need for simple, sensitive, and inexpensive methods for 
the determination of low levels of zinc in various samples collected from environment, biological fluid and water.

Many different techniques have been applied to the measurement of $\mathrm{Zn}$ (II) ions in a variety of samples, including atomic absorption-emission spectrophotometry (Sun et al., 2006) and electrochemical (Ge et al., 2003). Although they provide quantitative data, these methods have basic limitations in terms of equipment cost, complexity, sample processing and run times, and they are not appropriate for the direct analysis of $\mathrm{Zn}$ (II) ions because of their trace levels and matrix interferences in samples. For these reasons, preliminary preconcentration/separation and matrix-removal steps are frequently required to ensure the accuracy and precision of the analytical results.

Currently, the most widely used preconcentration methods are liquid-liquid microextraction (Liao et al., 2011; Pesavento et al., 2009), solid-phase extraction (SPE) (Panhwar et al., 2015; Liu, 2013), electrochemical deposition (Sun et al., 2000) and CPE.(Ohashi, 2004; Ulusoy et al., 2012). Separation and preconcentration based on CPE have attracted considerable attention in the last few years mainly because those procedures can decrease or eliminate the use or generation of toxic substances. It is in agreement with the "green chemistry" principles. Moreover, compared with the classical liquid-liquid extraction method, CPE technique has become increasingly popular due to its high enrichment factor, high recovery, rapid phase separation, low cost, low consumption of organic solvents and the ability of combination with different detection. CPE combined with many modern analytical techniques such as atomic absorption spectrometry (AAS), spectrophotometry have been used to measure the concentration of metal elements in samples from environmental to human (Baig et al., 2011; Song et al., 2016). Spectrophotometric analytical methods and instruments have been widely applied in analytical chemistry for decades and offered many appealing characteristics, including simple instrumentation, rapid response times, and easy operation (Zarei, 2007). Coupled some advanced preconcentration techniques with traditional spectrophotometer, trace or ultra-trace levels of metal ions could be successfully detected (Wen et al., 2011; Wen et al., 2011). Furthermore, 1-(2pyridylazo)-2-naphthol (PAN) is widely used in all kinds of metal detection as a wellknown benign ligand in CPE (Afkhami and Bahram, 2006).

Based on the above consideration, we described the new zinc UV-vis spectrophotometry analysis method based on the CPE by using $\mathrm{Zn}$ (II)-PAN complex. The $\mathrm{Zn}(\mathrm{II})-\mathrm{PAN}$ processed by the technology of CPE show the maximum absorption wavelength at $549 \mathrm{~nm}$. In the light of the absorption in visible region, we determined the concentration of $\mathrm{Zn}$ (II) ions by UV-vis spectrophotometry. The proposed method possesses the advantages of high enrichment factor, simplicity, sensitivity, low cost, selectivity and environmental benign. What is lack of the method is far too much manual handling, and the automation should be improved. This method was successfully applied to the determination of $\mathrm{Zn}$ (II) ions in water, soil and rabbit blood samples.

\section{Experiment}

\section{Reagents}

Stock standard solutions of $1000 \mathrm{mg} \cdot \mathrm{L}^{-1} \mathrm{Zn}$ (II) were prepared by dissolving $\mathrm{ZnSO}_{4}$ in $2 \%(\mathrm{v} / \mathrm{v}) \mathrm{HNO}_{3}$. Working solutions were obtained daily by stepwise dilution from standard stock solution with doubly-distilled water (DDW). The chelating reagent at 
$4 \times 10^{-3} \mathrm{~mol} / \mathrm{L}$ was prepared by dissolving PAN in ethanol. Both the non-ionic surfactant Triton X-100 and the surfactant SDS were purchased from Aladdin. In this work, 50 $\mathrm{g} / \mathrm{L}$.of Triton X-100 and 1\% (w/w) of SDS were prepared and used in this work. The $\mathrm{pH}$ of the solutions was adjusted by using $0.2 \mathrm{~mol} \cdot \mathrm{L}^{-1} \mathrm{NH}_{3} \cdot \mathrm{H}_{2} \mathrm{O}$ and $0.2 \mathrm{~mol} / \mathrm{L} \mathrm{NH}_{4} \mathrm{Cl}$. DDW was used throughout the work.

\section{Samples preparation}

River water was collected from Xi River and Huatan River (Nanchong, PR China), respectively. Tap water was freshly obtained from our laboratory after allowing the water to flow for $5 \mathrm{~min}$. All water samples above were filtered through a $0.45 \mu \mathrm{m}$ pore size membrane filter to remove suspended particulate matters prior to use.

The soil was sampled from the mountain, gardens and fields located in China West Normal University, respectively. Classification methods through four points were used to classify the soil collected, and these soil samples were dried at $120{ }^{\circ} \mathrm{C}$ for up to $24 \mathrm{~h}$ until constant dry weight was achieved. After removal of chunks of rock and grassroots, the dry soil samples were disaggregated in the ceramic mortar. The sample was sieved through a 100 -mesh sieve. The resulting samples were used for later zinc analysis. Tools used for this procedure such as the mortar and the sieve were washed with anhydrous ethanol before the sample processing.

A $5.0 \mathrm{~g}$ dried soil samples was weighted into a plastic tube and $0.1 \mathrm{~mol} / \mathrm{L} \mathrm{HCl}$ solution $(1: 10, \mathrm{v} / \mathrm{v})$ was added. The resulting mixture was subject to stirring evenly for overnight, followed by keeping in room temperature oscillation for $3 \mathrm{~h}$ and then filtering. The filtrate was transferred to a $100 \mathrm{~mL}$ volumetric flask and diluted it to the mark for zinc analysis.

Into a $100 \mathrm{~mL}$ conical flask was added $5.0 \mathrm{~mL}$ of rabbit blood sample and $5.0 \mathrm{~mL}$ of concentrated $\mathrm{HNO}_{3}$. The resulting solution was left at fumehood for overnight. After adding $2 \mathrm{~mL}$ of $30 \% \mathrm{H}_{2} \mathrm{O}_{2}$, the sample was evaporated to $1 \mathrm{~mL}$ on a thermo-regulated hot plate. This $1 \mathrm{~mL}$ solution was transferred to a $50 \mathrm{~mL}$-volumetric flask and diluted it to the mark for zinc analysis.

\section{Apparatus}

UV2550 ultraviolet and visible spectrophotometer (Shimadzu, Japan) was used for quantitative analysis of zinc. A centrifuge (Model TDZ5-WS) (Shanghai Lu Xiangyi centrifuge Instrument Co., Ltd, Shanghai, China) was employed to facilitate phase separation. The $\mathrm{pH}$ values were measured by Ohaus Starter $3 \mathrm{C} \mathrm{pH}$ meter (Pine Brook, NJ, USA).

\section{Operating procedure}

Into a $10 \mathrm{~mL}$ centrifuge tube containing an appropriate amount of standard solution of $\mathrm{Zn}(\mathrm{II})$, was added $0.14 \mathrm{~mL}$ of $4 \times 10^{-3} \mathrm{~mol} / \mathrm{L}$ PAN solution, $0.4 \mathrm{~mL}$ of buffer solution (ammonia and ammonium chloride buffer, $\mathrm{pH}=8.5$ ), $0.8 \mathrm{~mL}$ of $50 \mathrm{~g} / \mathrm{L}$ Triton $\mathrm{X}-100$ solution, $0.2 \mathrm{~mL}$ of $5 \%$ (w/w) SDS solution and $1.5 \mathrm{~mL}$ saturated $\mathrm{NaCl}$ solution. The resulting solution immediately appeared cloudy phenomenon. DDW was used to dilute the solution to the mark of $10 \mathrm{~mL}$ centrifuge tube followed by shaking well. The procedure is shown in Fig. 1. The solution containing the analyte was stored in the refrigerator for $30 \mathrm{~min}$ at around $0{ }^{\circ} \mathrm{C}$. Separation of the phases was achieved by centrifugating at $4000 \mathrm{rpm}$ for $10 \mathrm{~min}$. This reaction was not subject to cooling in an ice 
bath, because a mixed micelle consisting of SDS and Triton X-100 was used as an extracting agent in which the temperature of cloud point was $0{ }^{\circ} \mathrm{C}$. Anhydrous ethanol was added to the surfactant-rich phase $(200 \mu \mathrm{L})$ to reduce its viscosity and promote sample treatment prior to the analysis by UV-Vis spectrophotometer. Blank solution was also conducted in the same procedure and measured in parallel to the sample solutions. The extraction rates and recoveries were calculated according to the equations below:

$$
\begin{gathered}
\text { Extraction rate }(\%)=\left(\mathrm{m}_{\text {measured }} / \mathrm{m}_{\text {initial }}\right) \times 100 \% \\
\text { Recovery }(\%)=\left(\left(\mathrm{m}_{\text {measured }}-\mathrm{m}_{\text {initial }}\right) / \mathrm{m}_{\text {added }}\right) \times 100 \%
\end{gathered}
$$

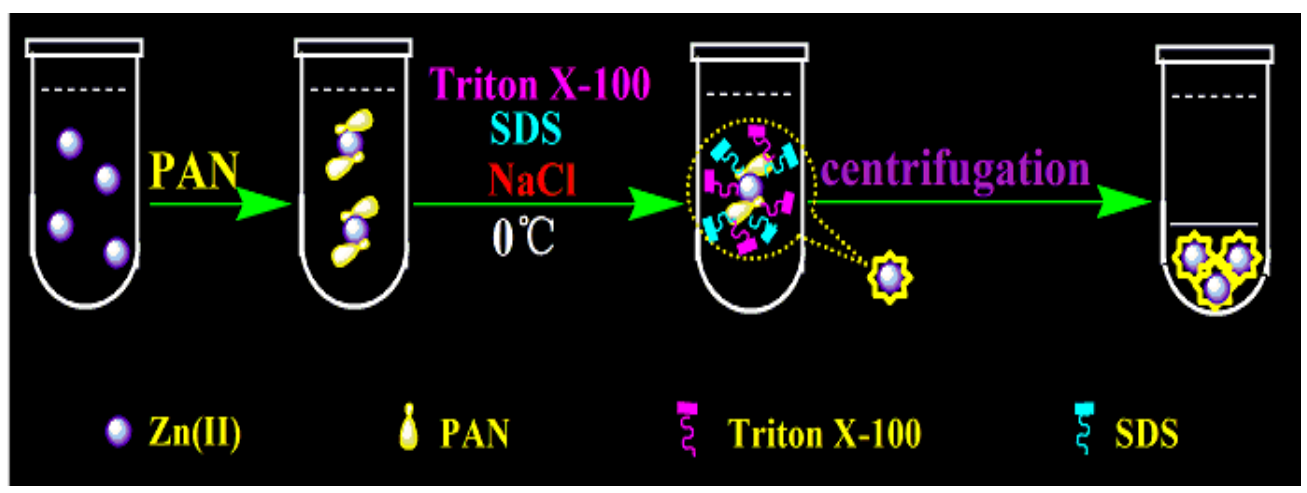

Figure 1. The procedure of cloud point extraction

\section{Results and discussion}

\section{Absorption spectra}

In this work, UV-vis spectrophotometry was coupled with the advanced CPE preconcentration to accomplish the determination of $\mathrm{Zn}(\mathrm{II})$ ions. The maximum wavelength of absorption of the complex of $\mathrm{Zn}$ (II)-PAN was the foundation of this quantitative analysis. Absorption spectra of different concentrations of $\mathrm{Zn}($ II )-PAN complex after CPE are shown in Fig. 2, indicating the maximum absorption wavelength was found at $549 \mathrm{~nm}$. The blank absorbance of all reagents utilized was subtracted in the process of the determination of zinc.

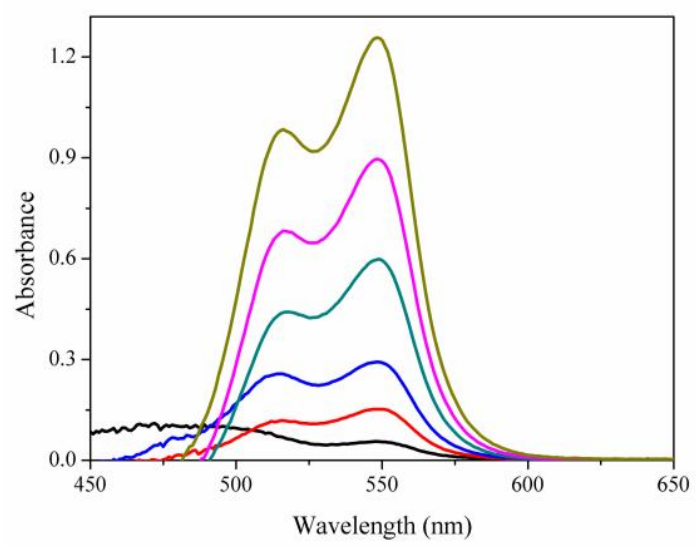

Figure 2. Absorption spectra of different concentrations of Zn(II)-PAN complex after CPE 


\section{Volume of the $\mathrm{NaCl}$}

According to reported, the CPT of mixed system of Triton X-100 and SDS was lowered to $0{ }^{\circ} \mathrm{C}$ after added a certain amount of $\mathrm{NaCl}$ solution, and then the phase separation was easier to achieve without heat, because they could lead to the rupture of hydrogen bonds of micelles and force the hydrophobic groups out of the water phase (Zhu et al., 2006). In order to assess the effect of the ionic strength in this work, the experiments were carried out by adding $\mathrm{NaCl}$ with different dosage $(0.4-2.0 \mathrm{~mL})$ to the solutions before CPE. As can be ascertained from Fig. 3, the extraction rate of $\mathrm{Zn}$ (II) ions is greatly increased with the volume of saturated $\mathrm{NaCl}$ added from 0.4 to $1.2 \mathrm{~mL}$. After that, the extraction rate of $\mathrm{Zn}$ (II) ions is remarkably decreased with the dosage of $\mathrm{NaCl}$ from 1.2 to $2.0 \mathrm{~mL}$. As a result, $1.2 \mathrm{~mL}$ was chosen as the optimal condition for the proposed method.

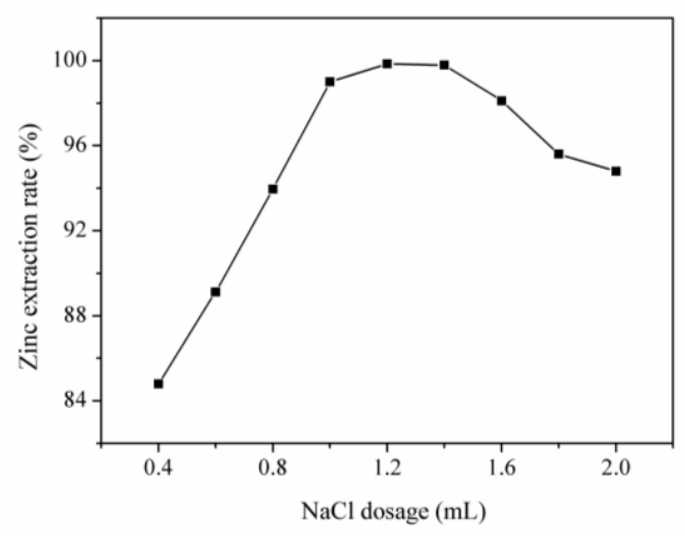

Figure 3. Effect of $\mathrm{NaCl}$ dosage on the extraction efficiency of $\mathrm{Zn}$ (II) ions. CPE conditions: $\mathrm{Zn}$ ( II) $(100 \mathrm{ng} / \mathrm{mL})$; SDS 0.1\% (w/w); Triton X-100, 0.4\% (v/v); PAN, $0.14 \mathrm{~mL}\left(4 \times 10^{-3} \mathrm{~mol} / \mathrm{L}\right)$ and $p H=8.5$

\section{Concentration of SDS}

In those established methods, SDS was used as cloud point revulsant and synergic reagent, which combined with Triton X-100 could reach a better result than those attainable with the individual components separately in the process of extraction of metal, which is known as synergism (Li et al., 2007). Furthermore, SDS also was used to decrease the CPT (Zhu et al., 2006). In this work, it was found that the CPT of TX100 was decreased to $0^{\circ} \mathrm{C}$ by adding SDS and the above $\mathrm{NaCl}$. $\mathrm{Zn}$ (II) ions can be separated from the resulting mixture when storing the extraction system in the refrigerator for about $30 \mathrm{~min}$. The impacts of the concentration of SDS on the zinc extraction rate were evaluated from $0.025 \%$ to $0.250 \%$. As shown in Fig. 4, the extraction rate of $\mathrm{Zn}$ (II) ions is increased by increasing the SDS concentration up to $0.1 \%$. When the SDS concentration exceeds $0.1 \%$, there is no any improvement observed in the zinc extraction rate. Such observations may be due to the fact that $0.1 \%$ SDS is good enough to completely extract zinc from the mixture. As a consequence, $0.1 \%$ SDS was selected in the following experiments. 


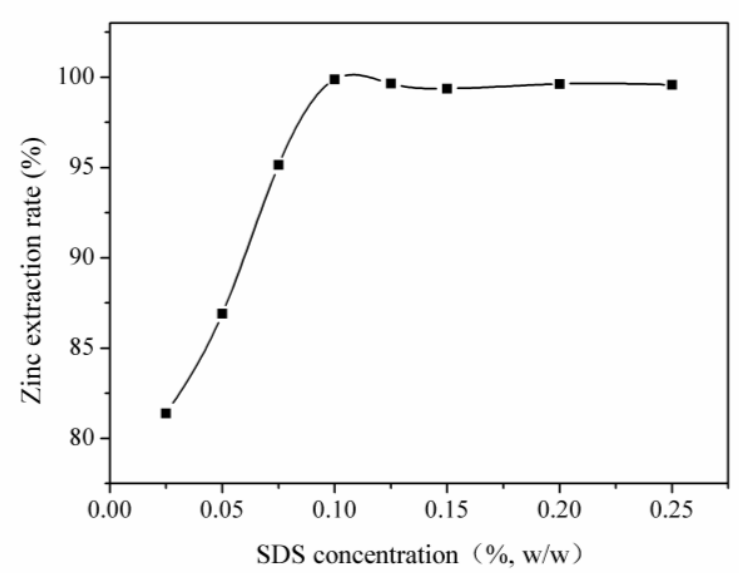

Figure 4. Effect of SDS concentration on the extraction efficiency of Zn (II) ions. CPE conditions: $\mathrm{Zn}(\mathrm{II}),(100 \mathrm{ng} / \mathrm{mL})$; saturated $\mathrm{NaCl}, 1.2 \mathrm{~mL}$; Triton $\mathrm{X}-100,0.4 \%(\mathrm{v} / \mathrm{v}) ; \mathrm{PAN}, 0.14$ $\mathrm{mL}\left(4 \times 10^{-3} \mathrm{~mol} / \mathrm{L}\right)$ and $\mathrm{pH}=8.5$

\section{Effect of $p H$}

The precondition of separation of metal ions by the CPE method involves the formation of a complex with sufficiently hydrophobic character being extracted into the small volume of the surfactant-rich phase. The extraction yield of $\mathrm{Zn}$ (II) ions may depend on the $\mathrm{pH}$ as $\mathrm{Zn}(\mathrm{II})$ ions and PAN can form stable compounds only under alkaline conditions. Therefore, the $\mathrm{CPE}$ of $\mathrm{Zn}$ (II) ions was performed in buffer solutions at a $\mathrm{pH}$ range of 7.0-11.0. The results are shown in Fig. 5. It can be seen that the extraction rate of $\mathrm{Zn}$ (II) ions is increased dramatically with an increase in $\mathrm{pH}$ up to 8.5. In contrast, when the $\mathrm{pH}$ is higher than 8.5, the extraction rate of $\mathrm{Zn}$ (II) ions is decreased with increasing $\mathrm{pH}$ and this observation may be due to the hydrolysis of $\mathrm{Zn}(\mathrm{II})$ ions. Hence the optimal buffer $\mathrm{pH}$ value was set at 8.5 for CPE.

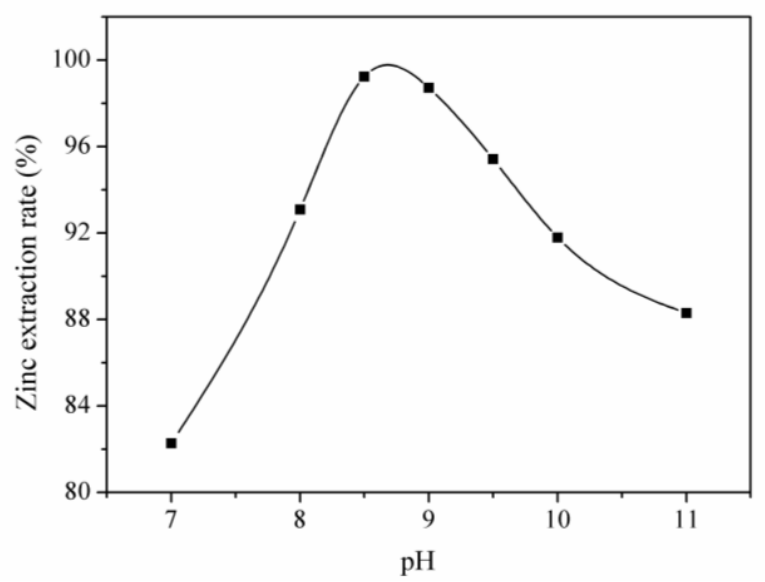

Figure 5. Effect of $p H$ on the extraction efficiency of $Z n(I I)$ ions. CPE conditions: $Z n$ (II), (100 $n g / m L) ;$ saturated $\mathrm{NaCl}, 1.2 \mathrm{~mL}$; SDS 0.1\% (w/w); Triton X-100, $0.4 \%(\mathrm{v} / \mathrm{v})$ and PAN, $0.14 \mathrm{~mL}$

$$
\left(4 \times 10^{-3} \mathrm{~mol} / \mathrm{L}\right)
$$




\section{Volume of the PAN}

The chelating concentration is very important to the CPE efficiency and subsequent $\mathrm{UV}$-vis spectrophotometer determination. As the principle reagent in this work, PAN was selected to form Zn-PAN complex. The effect of the chelating reagent dosage on the extraction efficiency was investigated in the range of 0.06-0.20 mL. As shown in Fig. 6, the extraction rate of $\mathrm{Zn}$ (II) ions is increased with an increase in the dosage of PAN from 0.06 to $0.14 \mathrm{~mL}$. The extraction rate is gradually decreased when the PAN dosage is higher than $0.14 \mathrm{~mL}$. The excessive PAN could be co-extracted into the surfactant rich phase, thus posting negative effects on the extraction efficiency of target analytes. Therefore, $0.14 \mathrm{~mL}$ PAN was chosen for the further study.

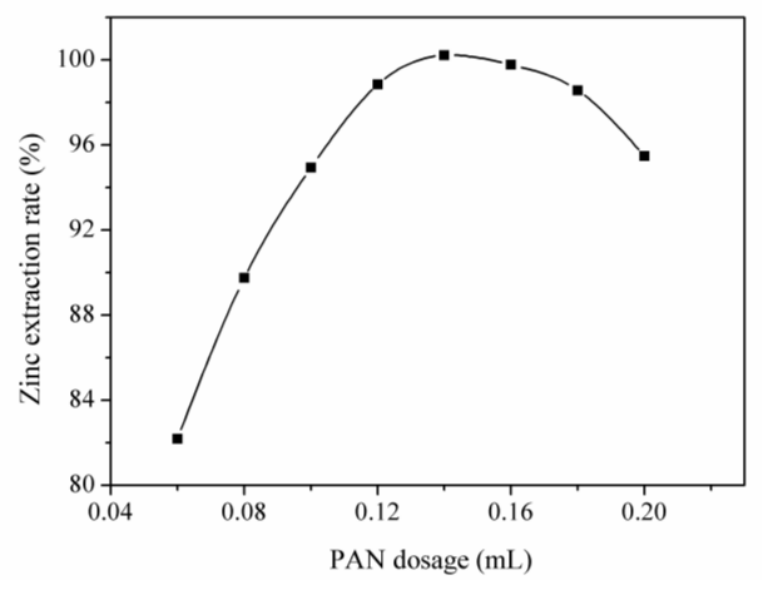

Figure 6. Effect of PAN dosage on the extraction efficiency of Zn (II) ions. CPE conditions: $\mathrm{Zn}(\mathrm{II}),(100 \mathrm{ng} / \mathrm{mL}) ;$ saturated $\mathrm{NaCl}, 1.2 \mathrm{~mL}$; SDS 0.1\% (w/w); Triton X-100, 0.4\% (v/v) and $p H=8.5$

\section{Effect of triton $X-100$ concentration}

A successful CPE would maximize the enrichment factor through minimizing the phase volume ratio. The surfactant concentration is the main parameter affecting the phase ratio. Triton $\mathrm{X}-100$ is one of the non-ionic surfactants extensively used in CPE because of its commercial availability with high purity, low toxicity, low cost and so on. Thus, the influence of different Triton X-100 concentrations on the CPE extraction efficiency of $\mathrm{Zn}$ (II) ions was examined, and the results are presented in Fig. 7. As can be seen, the extraction rate of $\mathrm{Zn}$ (II) ions is increased with an increase in Triton X-100 concentration up to $0.4 \%$, then reaching a plateau, which is considered as complete extraction. This observation (Fig. 7) is similar to that observed in Fig. 4 in which the influence of the different SDS concentrations on the extraction efficiency of $\mathrm{Zn}$ (II) ions is presented. So a concentration of $0.4 \%(\mathrm{v} / \mathrm{v})$ Triton X-100 was used for subsequent experiments. 


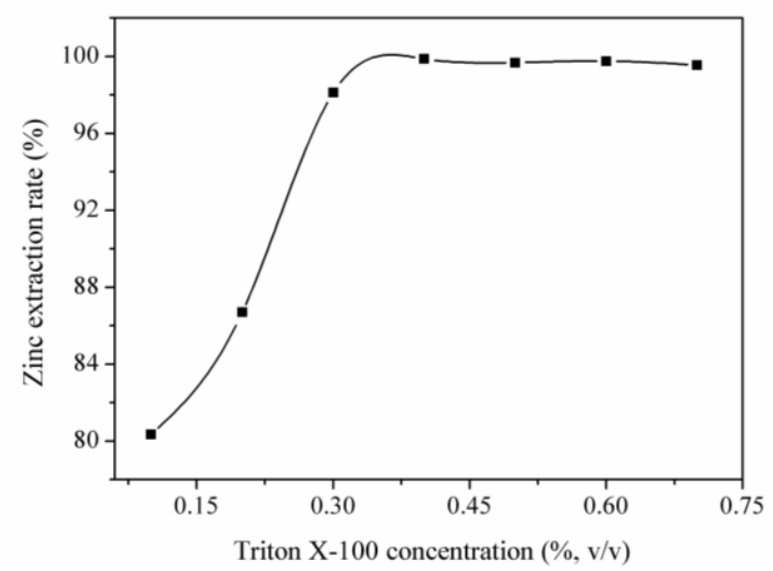

Figure 7. Effect of Triton X-100 concentration on the extraction efficiency of $\mathrm{Zn}(I I)$ ions. CPE conditions: $\mathrm{Zn}(\mathrm{II}),(100 \mathrm{ng} / \mathrm{mL})$; saturated $\mathrm{NaCl}, 1.2 \mathrm{~mL}$; SDS 0.1\% (w/w); PAN $0.14 \mathrm{~mL}$ $\left(4 \times 10^{-3} \mathrm{~mol} / \mathrm{L}\right)$ and $\mathrm{pH}=8.5$

\section{Interference study}

Because PAN is a universal chelating reagent which can coordinate with other metal elements, and interferences may occur due to the competition of other metal ions for PAN. In this work, several typically potential interfering metal ions were selected for the evaluation of the selectivity of the proposed $\mathrm{CPE}$, including $\mathrm{Na}(\mathrm{I}), \mathrm{K}(\mathrm{I}), \mathrm{Ca}$ (II), $\mathrm{Mg}(\mathrm{II}), \mathrm{Ni}(\mathrm{II}), \mathrm{Cu}(\mathrm{II}), \mathrm{Ba}(\mathrm{II}), \mathrm{Pb}(\mathrm{II}), \mathrm{Cd}(\mathrm{II}), \mathrm{Co}(\mathrm{II}), \mathrm{Mn}(\mathrm{II}), \mathrm{Cr}(\mathrm{III})$ as well as $\mathrm{Fe}(\mathrm{III}) . \mathrm{A}$ series of solutions of $100 \mathrm{ng} / \mathrm{mL} \mathrm{Zn(II)} \mathrm{containing} \mathrm{the} \mathrm{metal} \mathrm{ions} \mathrm{mentioned} \mathrm{above} \mathrm{at}$ different concentrations were prepared and determined by UV-vis spectrophotometry after CPE, respectively. The results are summarized in Table 1. indicating that all interfering ions of study have no obvious interference on the determination of zinc. According to studies in literature, most of the ions of investigation can form a complex with PAN, but the maximum absorption wavelength of all kinds of complex is different. In addition, most of these ions can be precipitated at $\mathrm{pH}$ 8.5. Therefore, the selectivity of this method was secured and fairly satisfactory.

Table 1. Investigation of interferences from co-existing metal ions on the determination of $100 \mathrm{ng} / \mathrm{mL} \mathrm{Zn}$ (II) by using CPE preconcentration followed by UVVis spectrophotometer determination

\begin{tabular}{ccc}
\hline Ions & Interference/metal ratio & Recovery, \% \\
\hline $\mathrm{Mg}(\mathrm{II})$ & 1000 & 100.2 \\
$\mathrm{Cu}(\mathrm{II})$ & 50 & 99.9 \\
$\mathrm{Mn}(\mathrm{II})$ & 500 & 93.6 \\
$\mathrm{~Pb}(\mathrm{II})$ & 500 & 91.2 \\
$\mathrm{Fe}(\mathrm{III})$ & 100 & 94.3 \\
$\mathrm{Na}(\mathrm{I})$ & 1000 & 102.8 \\
$\mathrm{Ni}(\mathrm{II})$ & 300 & 95.2 \\
$\mathrm{Ba}(\mathrm{II})$ & 1000 & 101.1 \\
$\mathrm{~K}(\mathrm{I})$ & 1000 & 105.2 \\
$\mathrm{Ca}(\mathrm{II})$ & 1000 & 100.7 \\
$\mathrm{Cd}(\mathrm{II})$ & 300 & 93.5 \\
$\mathrm{Cr}(\mathrm{III})$ & 30 & 98.7 \\
$\mathrm{Co}(\mathrm{II})$ & 50 & 95.3 \\
\hline
\end{tabular}




\section{Analytical figures of merit}

Analytical figures of merit of the developed CPE-UV-vis spectrophotometric method for the determination of zinc were evaluated. Under the optimal experimental conditions, some characteristics of this method such as linear range, correlation coefficients, limit of detection (LOD), repeatability and enrichment factor were investigated, respectively. The calibration curve was linear in the range of 10-1000 $\mathrm{ng} / \mathrm{mL} \mathrm{Zn}(\mathrm{II})\left(\mathrm{R}^{2}>0.997\right)$ and the linear equation was $\mathrm{A}=0.00291 \mathrm{C}+0.001914$ (where $\mathrm{A}$ is the absorbance and $\mathrm{C}$ is the concentration of $\left.\mathrm{Zn}(\mathrm{II}), \mathrm{ng} \cdot \mathrm{mL}^{-1}\right)$. The detection limit (LOD) of this method calculated as three times the standard deviation of eleven replicate measurements of the blank solution using the CPE method was $3.3 \mathrm{ng} / \mathrm{mL}$. Relative standard deviations (RSD) for eleven replicate determinations $100 \mathrm{ng} / \mathrm{mL}$ of $\mathrm{Zn}$ (II) was $2.8 \%$. The enrichment factor which was calculated as the ratio of the slopes for the calibration curves subjected to preconcentration procedure and direct sampling (without preconcentration) was 38 .

\section{Application}

In order to confirm the applicability of the proposed method, it has been applied to the determination of $\mathrm{Zn}$ (II) ions in water, soil and biological samples. The reliability of the presented method was proved by spiking experiments and independent analysis. The results of this study shown in Table 2 indicate that the recoveries are in the range of 97.7-101.5\% and confirm the accuracy of the method and independence from the matrix effects.

Table 2. Determination of zinc (II) in water samples, soils and rabbit blood samples by the proposed method

\begin{tabular}{ccccc}
\hline Samples & Added, $\mathbf{( n g} / \mathbf{m L})$ & Found, $\mathbf{( n g} / \mathbf{m L})$ & R.S.D, $\%$ & Recovery, \% \\
\hline & 0 & 27.5 & 1.5 & - \\
Tap water & 100 & 127.7 & 1.7 & 100.2 \\
& 400 & 427.0 & 1.2 & 99.8 \\
River water & 0 & 48.5 & 1.8 & - \\
(Huatan river) & 100 & 148.1 & 1.3 & 99.6 \\
& 400 & 440.9 & 1.6 & 98.1 \\
River water & 0 & 49.7 & 1.4 & - \\
(Jialing river) & 100 & 149.6 & 1.5 & 99.9 \\
& 400 & 454.4 & 1.7 & 101.2 \\
Rabbit blood & 0 & 185.3 & 2.5 & - \\
sample & 100 & 283.0 & 3.1 & 97.7 \\
& 400 & 587.9 & 3.0 & 100.7 \\
Mountain soil & 0 & 147.2 & 2.4 & - \\
& 100 & 245.3 & 2.9 & 98.1 \\
Garden soil & 400 & 548.8 & 2.3 & 100.4 \\
& 0 & 161.7 & 3.0 & - \\
Cultivated soil & 100 & 262.9 & 2.7 & 101.2 \\
& 400 & 562.9 & 2.1 & 100.3 \\
\hline
\end{tabular}




\section{Conclusions}

The method of CPE combined with UV-vis spectrophotometry for the determination of trace zinc was successfully established. The surfactant Triton X-100 was used as the extractant and SDS worked as cloud point revulsant and synergic reagent for extraction, which lowered the CPT of Triton X-100 more than $60{ }^{\circ} \mathrm{C}$ and assisted the subsequent extraction process. The limit of detection for $\mathrm{Zn}(\mathrm{II})$ was $3.3 \mathrm{ng} / \mathrm{mL}$, with sensitivity enhancement factor (EF) of 38. The methodology offers a simple, highly sensitive and selective, cost-effective and environmental benign alternative that can be applied to the determination of zinc in various samples collected from environment, biological fluid and water with satisfactory analytical results.

Acknowledgements. This work was supported by the National Natural Science Foundation of China (no. 21277109), the Program for Young Scientific and Technological Innovative Research Team in Sichuan Province (2014TD0020) and the Sichuan Province Science and Technology Support Plan Project (2015SZ0204).

\section{REFERENCES}

[1] Afkhami, A., Bahram, M., (2006): Cloud point extraction simultaneous spectrophotometric determination of $\mathrm{Zn}(\mathrm{II}), \mathrm{Co}(\mathrm{II})$ and $\mathrm{Ni}$ (II) in water and urine samples by 1 -(2-pyridylazo) 2-naphthol using partial least squares regression. - Microchimca Acta 155: 403-407.

[2] Baig, J. A., Kazi, T. G., Arain, M. B., Shah, A. Q., Kandhro, G. A., Afridi, H. I., Khan, S., Kolachi, N. F., Wadhwa, S. K. (2011): Inorganic arsenic speciation in groundwater samples using electrothermal atomic spectrometry following selective separation and cloud point extraction. - Analytical Sciences 27: 439-445.

[3] Berg, J. M., Shi, Y. (1996): The galvanization of biology: a growing appreciation for the roles of zinc. - Science 271: 1081-1085.

[4] Falchuk, K. H. (1998): The molecular basis for the role of zinc in developmental biology. - Molecular and Cellular Biochemistry 188: 41-48.

[5] Fischer-Walker, C., Black, R. E. (2004): Zinc and the risk for infectious disease. Annual Review of Nutrition 24: 255-275.

[6] Frederickson, C. J., Koh, J. Y., Bush, A. I. (2005): The neurobiology of zinc in health and disease. - Nature Reviews Neuroscience 6: 449-462.

[7] Galbeiro, R., Garcia, S., Gaubeur, I. (2014): A green and efficient procedure for the preconcentration and determination of cadmium, nickel and zinc from freshwater, hemodialysis solutions and tuna fish samples by cloud point extraction and flame atomic absorption spectrometry. - Journal of Trace Elements in Medicine and Biology, 28(28): 160-165.

[8] Ge, B., Scheller, F. W., Lisdat, F. (2003): Electrochemistry of immobilized CuZnSOD and FeSOD and their interaction with superoxide. - Biosensors and Bioelectronics 18: 295-302.

[9] Hambidge, K. M., Krebs, N. F. (2007): Zinc deficiency: a special challenge. - Journal of Nutrition 137940: 1101-1105.

[10] Ho, E. (2004): Zinc deficiency, DNA damage and cancer risk. - Journal of Nutritional Biochemistry. 15: 572-578.

[11] Koh, J. Y., Suh, S. W., Gwag, B. J., He, Y. Y., Hsu, C. Y., Choi, D. W. (1996): The role of zinc in selective neuronal death after transient global cerebral ischemia. - Science 272: 1013-1016. 
[12] Li, Y., He, X. J., Cao, X. L., Zhao, G. Q., Tian, X. X., Cui, X. H. (2007): Molecular behavior and synergistic effects between sodium dodecylbenzene sulfonate and Triton X100 at oil/water interface. - Journal of Colloid and Interface Science 307(1): 215-220.

[13] Liao, X. X., Liang, B., Li, Z. Z. Li, Y. F. (2011): A simple, rapid and sensitive ultraviolet-visible spectrophotometric technique for the determination of ultra-trace copper based on injection-ultrasound-assisted dispersive liquid-liquid microextraction. Analyst 136(21): 4580-4586.

[14] Liu, Z. L. (2013): Fractal theory and application in city size distribution. - Information Technology Journals 12(7): 4158-4162.

[15] Mansur, M. B., Rocha, S. D. F., Magalhães, F. S. Benedetto, J. S. (2008): Selective extraction of zinc(II) over iron(II) from spent hydrochloric acid pickling effluents by liquid-liquid extraction. - Journal of Hazardous Materials 150: 669-678.

[16] O'Halloran, T. V. (1993): Transition metals in control of gene expression. - Science 261: 715-725.

[17] Ohashi, A., Tsuguchi, A., Imura, H., Ohashi, K. (2004): Synergistic Cloud Point Extraction Behavior of Alumi num(III) with 2-Methyl-8-quinolinol and 3,5Dichlorophenol. - Analytical Science 20: 1091-1093.

[18] Panhwar, A. H., Kazi, T. G., Afridi, H. I. Arain, S. A., Brahman, N. K. D., Arain, M. S. (2015): A new solid phase microextraction method using organic ligand in micropipette tip syringe system packed with modified carbon cloth for preconcentration of cadmium in drinking water and blood samples of kidney failure patients. - Spectrochimica Acta Part A 138: 296-302.

[19] Pesavento, M., Alberti, G., Biesuz, R. (2009): Analytical methods for determination of free metal ion concentration, labile species fraction and metal complexation capacity of environmental waters: A review. - Analytica Chimica Acta 631: 129-141.

[20] Song, S. G., Li, X. P., Margaris, D. P. (2016): Electric vehicle electric-hydraulic regenerative braking strategy based on variable current feedback. - Journal of Mechanical Engineering Research and Developments 39(2): 403-412.

[21] Sun, Y. C., Mierzwa, J., Lan, C. R. (2000): Direct determination of molybdenum in seawater by adsorption cathodic stripping square-wave voltammetry. - Talanta, 52: 417424.

[22] Sun, Z., Liang, P., Ding, Q., Cao, J. (2006) Cloud point extraction preconcentration of manganese(II) from natural water samples using 1-phenyl-3-methyl-4-benzoyl-5pyrazolone and triton $\mathrm{X}-100$ and determination by flame atomic absorption spectrometry. - Analytical Science 22: 911-913.

[23] Tsvetkov, P. O., Popov. I.r A., Nikolaev, E. N., Archakov, A. I., Makarov, A. A., Kozin, S. A. (2008): Isomerization of the Asp7 residue results in zinc-Induced oligomerization of alzheimer's disease amyloid $\beta(1-16)$ peptide. - Biochemistry 9(10): 1564-1567.

[24] Ulusoy, H. I., Gürkan, R., Ulusoy, S. (2012): Cloud point extraction and spectrophotometric determination of mercury species at trace levels in environmental samples. - Talanta 88: 516-523.

[25] Vallee, B. L., Falchu, K. H. (1993): The biochemical basis of zinc physiology. Physiological Reviews 73: 79-118.

[26] Wan, R., Kong, D. Q., Liu, J. P. (2016): Study on outdoor high temperature for summer air conditioning by gumbel distribution model. - Journal of Mechanical Engineering Research and Developments 39(2): 296-302.

[27] Wei, G., Hough, C. J., Li, Y., Sarvey. J. M. (2004): Characterization of extracellular accumulation of $\mathrm{Zn}^{2+}$ during ischemia and reperfusion of hippocampus slices in rat. Neuroscience 125: 867-877.

[28] Wen, X. D., Deng, Q. W., Guo, J., Yang, S. C. (2011): Ultra-sensitive determination of cadmium in rice and water by UV-vis spectrophotometry after single drop microextraction. - Spectrochimica Acta Part A 79: 508-512. 
[29] Wen, X. D., Yang, Q. L., Yan, Z. D., Deng, Q.W. (2011): Determination of cadmium and copper in water and food samples by dispersive liquid-liquid microextraction combined with UV-vis spectrophotometry. - Microchemical Journal 97: 249-254.

[30] Zarei, A. R. (2007): Cloud point formation based on mixed micelle in the presence of electrolyte for extraction, preconcentration, and spectrophotometric determination of trace amounts of hydrazine in water and biological samples. - Analytical Biochemistry 369: 161-167.

[31] Zhu, X. H., Zhu, X. S., Wang, B. S. (2006): Cloud point extraction for speciation analysis of inorganic tin in water samples by graphite furnace atomic absorption spectrometry. Journal of Analytical Atomic Spectrometry 21: 69-73. 